\title{
Involvement of leptin in the association between percentage of body fat and cardiovascular risk factors
}

\author{
Javier Gómez-Ambrosi ${ }^{\mathrm{a}, *}, J$ avier Salvador ${ }^{\mathrm{b}}$, Jose A. Páramo ${ }^{\mathrm{c}}$, Josune Orbe ${ }^{\mathrm{c}}$, Jokin de Irala ${ }^{\mathrm{d}}$, \\ Alberto Diez-Caballero ${ }^{\mathrm{e}}$, María J. Gil ${ }^{\mathrm{f}}$, Javier A. Cienfuegos ${ }^{\mathrm{e}}$, Gema Frühbeck ${ }^{\mathrm{a}, \mathrm{b}}$ \\ a Metabolic Research Laboratory, Clínica Universitaria de Navarra, Pamplona, Spain \\ ${ }^{\mathrm{b}}$ Department of Endocrinology, Clínica Universitaria de Navarra, Pamplona, Spain \\ ${ }^{\mathrm{c}}$ Atherosclerosis Research Unit, Division of Cardiovascular Pathophysiology and Biochemistry, University of Navarra, Pamplona, Spain \\ ${ }^{\mathrm{d}}$ Department of Epidemiology and Public Health, University of Navarra, Pamplona, Spain \\ ${ }^{\mathrm{e}}$ Department of Surgery, Clínica Universitaria de Navarra, Pamplona, Spain \\ ${ }_{\mathrm{f}}^{\mathrm{f}}$ Department of Biochemistry, Clínica Universitaria de Navarra, Pamplona, Spain
}

Received 5 February 2002; received in revised form 6 May 2002; accepted 8 May 2002

\begin{abstract}
Objectives: Recent epidemiologic studies have shown that obesity is associated with elevated blood concentrations of prothromboticproinflammatory factors and markers of endothelial dysfunction such as fibrinogen, C-reactive protein (CRP), von Willebrand factor (vWF), and homocysteine. We have assessed whether these markers are associated with percentage of body fat (BF), insulin sensitivity as well as with leptin concentrations.

Design and methods: Twenty-five men aged $49.6 \pm 12.7 \mathrm{yr}$ (mean $\pm \mathrm{SD}$ ) underwent whole-body air displacement plethysmography $\left(\right.$ Bod-Pod $^{\circledR}$ ) for estimating BF. Blood analyses for leptin and several other metabolic and cardiovascular markers were carried out.

Results: Obese subjects had higher levels as compared to controls of BF (37.5 \pm 5.1 vs. $26.0 \pm 6.6, p<0.01)$, fibrinogen $(3.30 \pm 0.43$ vs. $2.67 \pm 0.11, p<0.01)$, vWF $(136.4 \pm 50.4 \%$ vs. $81.6 \pm 12.6 \%, p<0.05)$, and leptin $(17.6 \pm 8.7$ vs. $6.2 \pm 3.3, p<0.01)$, lower concentrations of HDL-cholesterol $(1.09 \pm 0.20$ vs. $1.51 \pm 0.10, p<0.001)$ and lower QUICKI $\left(1 /\left[\log \left(\operatorname{Ins}_{0}\right)+\log \left(\mathrm{Glu}_{0}\right)\right]\right)(0.31 \pm 0.03$ vs. $0.34 \pm 0.02, p<0.05)$. No significant changes were observed in CRP $(5.7 \pm 3.4$ vs. $3.8 \pm 1.6, p=0.327)$ and homocysteine $(9.4 \pm$ 4.2 vs. $8.3 \pm 0.9, p=0.749)$. A positive correlation was observed between $\mathrm{BF}$ and fibrinogen $(\mathrm{r}=0.67, p=0.0003)$. Plasma leptin concentrations were correlated with fibrinogen $(\mathrm{r}=0.71, p=0.0001)$ and CRP $(\mathrm{r}=0.43, p=0.044)$. After adjustment for BF leptin emerged as a significant predictor of fibrinogen $\left(\beta=0.47, p=0.023 ; R^{2}=0.59, p<0.001\right)$. QUICKI was positively correlated with HDL-cholesterol $(\mathrm{r}=0.59, p=0.010)$ and negatively with fibrinogen $(\mathrm{r}=-0.53, p=0.025)$, CRP $(\mathrm{r}=-0.52, p=0.028)$ and $\mathrm{vWF}$ $(\mathrm{r}=-0.56, p=0.013)$.

Conclusions: Increased BF and impaired insulin sensitivity are associated with increased concentrations of cardiovascular risk factors. Leptin seems to be involved in this elevation and emerges as a predictor of circulating fibrinogen concentrations. (C) 2002 The Canadian Society of Clinical Chemists. All rights reserved.
\end{abstract}

Keywords: Obesity; Cardiovascular risk; Leptin; Fibrinogen; Insulin sensitivity

\section{Introduction}

Obesity is the most prevalent nutritional disorder in industrialized countries and is a growing problem in developing countries [1,2]. It is defined by an excess of body fat (BF) and is generally accompanied by insulin resistance [3]. Both situations lead to an increase in circulating cardiovas-

\footnotetext{
* Corresponding author. Tel.: +34-948-42-56-00 (ext. 6567); fax: +34-948-42-56-52.

E-mail address: jagomez@unav.es (J. Gomez-Ambrosi).
}

cular risk factors, which may be the origin of cardiovascular diseases (CVD).

The mechanisms by which increased adiposity leads to insulin resistance and CVD are poorly understood. Adipose tissue has been previously considered to be a passive storage depot of energy. However, current evidence shows that adipocytes play an active role in metabolism through the secretion of hormones and cytokines involved in whole-body energy homeostasis [4]. These include leptin, adipsin, adiponectin, angiotensinogen, resistin, plasminogen-activator inhibitor-1 (PAI-1), tumor 
necrosis factor- $\alpha$ (TNF- $\alpha$ ), and interleukin-6 (IL-6), among others.

Leptin is a $16 \mathrm{kDa}$ hormone secreted mainly by adipocytes, although expression in placenta, fetal tissues, stomach and other tissues has also been observed. Leptin informs the brain about the size of the fat stores and has a wide variety of central and peripheral actions, including effects on reproduction, immune system, blood pressure, and angiogenesis [5].

Recent evidence suggests that leptin may be involved in the development of CVD. Leptin has been associated with impaired fibrinolysis [6,7], hypertension [8] and calcification of vascular cells [9]. In addition, plasma leptin concentrations are raised in patients with congestive heart failure [10] and correlate with heart rate in heart transplant recipients [11]. Moreover, some authors have proposed hyperleptinemia as a component of a metabolic syndrome of cardiovascular risk [12] while others have shown that leptin is an independent risk factor for coronary events in hypercholesterolemic men [13].

The present study tests the hypothesis that the increase in blood concentrations of several cardiovascular risk factors in obese subjects could be related to high fat mass and high concentrations of leptin. Therefore, the aim of this work was to assess whether several cardiovascular risk factors are associated with percentage of $\mathrm{BF}$, insulin sensitivity, as well as leptin concentrations.

\section{Methods}

\subsection{Subjects}

Patients were recruited from obese persons visiting the Endocrinology Department at the University Clinic of $\mathrm{Na}$ varra for weight loss treatment and were otherwise healthy. Sex- and age-matched healthy controls were recruited among hospital staff. The study included 25 men aged $49.6 \pm 12.7 \mathrm{yr}$, represented by 20 obese patients and 5 nonobese controls. Nonobese subjects were defined as having a body mass index $(\mathrm{BMI})<30 \mathrm{~kg} / \mathrm{m}^{2}$, whereas subjects with a BMI of 30 or more were classified as obese. The examinations and blood collections were carried out in the morning after a 12-h fast. All participants gave written informed consent to participate in the present study, which was approved by the Hospital's Ethical Committee.

\subsection{Anthropometric measurements}

Body weight and height were measured using standardized procedures. BMI was calculated as weight in $\mathrm{kg}$ divided by the square of height in meters. The 1998 clinical guidelines were used to define obesity (BMI $\geq 30$ ) [14]. Body fat was estimated by air-displacement-plethysmography (Bod-Pod ${ }^{\circledR}$, Life Measurements, Concord, CA, USA) [15 to 17]. This method has been reported to agree closely with the traditional gold standard hydrodensitometry (underwater weighing). Furthermore, the Bod-Pod ${ }^{\circledR}$ has been shown to predict fat mass and fat-free mass more accurately than dual-energy X-ray absorptiometry and bioelectrical impedance [15-17].

\subsection{Blood analyses}

Serum glucose was analyzed by an automated analyzer (Hitachi 717), with quantification being based on the enzymatic colorimetric reactions described by Trinder [18]. Insulin was measured by means of an enzyme-amplified chemiluminescence assay (IMMULITE ${ }^{\circledR}$, Diagnostic Products Corp., Los Angeles, CA, USA). Total cholesterol and triglyceride concentrations were determined by enzymatic spectrophotometric methods (Boehringer Mannheim, Mannheim, Germany). High-density lipoprotein (HDL-cholesterol) was quantified by a colorimetric method in a Beckman Synchron ${ }^{\circledR}$ CX analyzer (Beckman Instruments, Ltd., Bucks, UK). Low-density lipoprotein (LDL-cholesterol) was calculated by the Friedewald formula [19].

Fibrinogen concentrations were determined according to the method of Clauss [20] using a commercially available kit (Hemoliance ${ }^{\circledR,}$ Instrumentation Laboratory, Barcelona, Spain). Measurement of von Willebrand factor (vWF) antigen was performed by a micro-latex immunoassay (Diagnostica Stago, Inc., Parsippany, NJ, USA). A standard curve was prepared with a universal reference (NISBC 91/666) and the results were expressed as percentage of the standard. Intra-and inter-assay coefficients of variation were between $4.0 \%$ and $8.0 \%$. The concentrations of C-reactive protein (CRP) were analyzed by means of an immunoturbidimetric assay (Boehringer Mannheim) after calibration with the standard CRM 470. Homocysteine was determined applying a fluorescence polarization immunoassay (Axis Biochemicals ASA, Oslo, Norway), using an $\mathrm{IMx}^{\circledR}$ analyzer (Abbott Laboratories, Abbott Par, IL, USA). Leptin was measured by a double-antibody RIA method (Linco Research, Inc., St. Charles, MO, USA). Intra-and inter-assay coefficients of variation were $5.0 \%$ and $4.5 \%$, respectively.

\subsection{Calculation of insulin sensitivity}

Insulin sensitivity was calculated by using the quantitative insulin sensitivity check index (QUICKI) [21]. This index represents a simple accurate method for assessing insulin sensitivity in humans and is defined as $1 /(\log [$ insu$\left.\operatorname{lin}_{0}\right]+\log \left[\right.$ glucose $\left.\left._{0}\right]\right)$. QUICKI has been shown to correlate better than the homeostasis model assessment (HOMA) with the minimal model index of insulin sensitivity $\left(\mathrm{SI}_{\mathrm{MM}}\right)$ and the gold standard method, namely the hyperinsulinemic isoglycemic glucose clamp ( $\left.\mathrm{SI}_{\text {clamp}}\right)$.

\subsection{Statistical analysis}

Data are presented as mean \pm standard deviation (SD). Differences between groups were analyzed by Mann-Whit- 
Table 1

Characteristics of the obese and non-obese subjects

\begin{tabular}{lccc}
\hline & $\begin{array}{l}\text { Obese } \\
(n=20)\end{array}$ & $\begin{array}{l}\text { Non-obese } \\
(n=5)\end{array}$ & $p^{\mathrm{a}}$ \\
\hline Age (years) & $47.8 \pm 13.3$ & $56.8 \pm 7.6$ & 0.1531 \\
Body fat $(\%)$ & $37.5 \pm 5.2$ & $26.0 \pm 6.6$ & 0.0022 \\
BMI $\left(\mathrm{kg} / \mathrm{m}^{2}\right)$ & $35.1 \pm 4.8$ & $25.4 \pm 3.4$ & 0.0014 \\
Glucose $(\mathrm{mmol} / \mathrm{L})$ & $6.1 \pm 2.5$ & $5.3 \pm 0.5$ & 0.8364 \\
Insulin $(\mathrm{pmol} / \mathrm{L})$ & $130.6 \pm 92.6$ & $71.0 \pm 43.8$ & 0.0604 \\
QUICKI & $0.31 \pm 0.03$ & $0.34 \pm 0.02$ & 0.0465 \\
\hline
\end{tabular}

Data are mean \pm SD. BMI = body mass index; QUICKI $=$ quantitative insulin sensitivity check index.

${ }^{\text {a }}$ Mann-Whitney U-test comparing values between obese and non-obese groups.

ney U tests. Pearson's correlation coefficients (r) were computed to explore the correlations between two variables. Interrelationships were assessed using a multivariate regression analysis. The calculations were performed using the SPSS/Windows version 9.0.1 statistical package (SPSS, Chicago, IL, USA). A $p$ value lower than 0.05 was considered statistically significant.

\section{Results}

Clinical characteristics of the patients are summarized in Table 1. No statistically significant differences for age were found between the groups. As expected, BF as well as BMI were significantly higher $(p<0.01)$ in the obese subjects. No differences were found in circulating concentrations of glucose and insulin between the two groups. However, the QUICKI index, a method for assessing insulin sensitivity, was significantly reduced $(p<$ $0.05)$ in the obese individuals. Although total as well as LDL-cholesterol concentrations were higher in the obese group, they did not reach statistical significance. Triglycerides were significantly increased $(p<0.01)$ and HDLcholesterol was significantly reduced $(p<0.001)$ in the obese group (Table 2).

Prothrombotic factors such as fibrinogen and vWF were significantly increased $(p<0.01$ and $p<0.05$, respectively) in the obese subjects. CRP, a marker of systemic

Table 2

Lipid profile of the obese and non-obese subjects

\begin{tabular}{llll}
\hline & $\begin{array}{l}\text { Obese } \\
(n=20)\end{array}$ & $\begin{array}{l}\text { Non-obese } \\
(n=5)\end{array}$ & $p^{\mathrm{a}}$ \\
\hline Triglycerides (mmol/L) & $2.50 \pm 2.36$ & $0.93 \pm 0.17$ & 0.0016 \\
Total-Cholesterol (mmol/L) & $5.99 \pm 1.41$ & $5.05 \pm 1.00$ & 0.0596 \\
LDL-Cholesterol (mmol/L) & $3.75 \pm 1.03$ & $3.14 \pm 0.97$ & 0.1259 \\
HDL-Cholesterol (mmol/L) & $1.09 \pm 0.20$ & $1.51 \pm 0.10$ & 0.0007 \\
\hline
\end{tabular}

Data are mean $\pm \mathrm{SD}$

${ }^{\text {a }}$ Mann-Whitney U-test comparing values between obese and non-obese groups.
Table 3

Cardiovascular risk factors of the obese and non-obese subjects

\begin{tabular}{lccc}
\hline & $\begin{array}{l}\text { Obese } \\
(n=20)\end{array}$ & $\begin{array}{l}\text { Non-obese } \\
(n=5)\end{array}$ & $p^{\mathrm{a}}$ \\
\hline Fibrinogen $(\mathrm{g} / \mathrm{L})$ & $3.30 \pm 0.43$ & $2.67 \pm 0.11$ & 0.0067 \\
von Willebrand factor $(\%)$ & $136.4 \pm 50.4$ & $81.6 \pm 12.6$ & 0.0108 \\
C-reactive protein $(\mathrm{mg} / \mathrm{L})$ & $5.7 \pm 3.4$ & $3.8 \pm 1.6$ & 0.3269 \\
Homocysteine $(\mu \mathrm{mol} / \mathrm{L})$ & $9.4 \pm 4.2$ & $8.3 \pm 0.9$ & 0.7489 \\
Leptin $(\mathrm{ng} / \mathrm{mL})$ & $17.6 \pm 8.7$ & $6.2 \pm 3.3$ & 0.0028 \\
\hline
\end{tabular}

Data are mean $\pm \mathrm{SD}$.

${ }^{a}$ Mann-Whitney U-test comparing values between obese and non-obese groups.

inflammation, although being $50 \%$ increased in the obese group did not show significant differences. Concentrations of homocysteine were similar in both groups. As expected, leptin concentrations were significantly higher $(p<0.01)$ in the obese patients (Table 3).

To analyze the influence of $\mathrm{BF}$, leptin, and insulin resistance in the concentrations of the cardiovascular risk factors studied, correlations and multivariate regression analysis were performed. Circulating concentrations of fibrinogen were positively correlated with BF (Fig. 1A). Furthermore, a stronger correlation between fibrinogen and leptin concentrations was found (Fig. 1B). Although no statistical correlation between BF and CRP was found (Fig. 2A), the latter was positively correlated with leptin (Fig. 2B). The QUICKI index was negatively correlated with fibrinogen, CRP and vWF, and positively correlated with HDL-cholesterol (Figs. 3 and 4).

To assess the importance of the correlation of leptin with both fibrinogen and CRP and to discard the potential underlying effect of increased BF, a multiple linear regression analysis was carried out, with both fibrinogen and CRP as dependent variables and leptin and BF as independent variables. Leptin emerged as a significant predictor of fibrinogen concentrations after adjustment for $\mathrm{BF}\left(\beta=0.47, p=0.023 ; R^{2}=0.59, p<0.001\right)$ contributing to $55 \%$ of its variability. However, this was not the case with CRP, whose correlation with leptin disappeared after correction for BF.
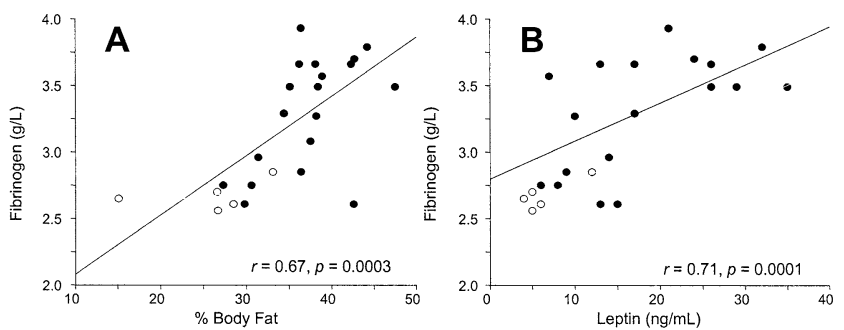

Fig. 1. Correlations of BF (A) and leptin (B) with circulating concentrations of fibrinogen of obese $(\boldsymbol{O})$, or nonobese $(\bigcirc)$ patients. Pearson's correlation coefficient $(r)$ and $p$ values are indicated. 

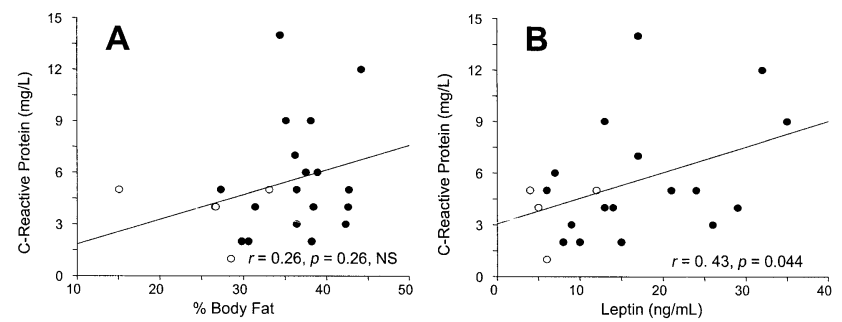

Fig. 2. Correlations of BF (A) and leptin (B) with circulating concentrations of C-reactive protein of obese $(\mathbf{O})$, or nonobese $(\bigcirc)$ patients. Pearson's correlation coefficient $(r)$ and $p$ values are indicated.

\section{Discussion}

Growing scientific and medical data supports the evidence that increased fat mass is associated with development of CVD [22-24]. In line with this fact, the American Heart Association included obesity as a major risk factor for coronary heart disease in 1998 [25]. The present study shows that increased BF and insulin resistance are related to several markers of inflammation and endothelial dysfunction, and that leptin is probably involved in this association.

Our results confirm earlier data reporting increased fibrinogen and vWF concentrations in obesity [26-28], thus reinforcing the observation that increased fat mass may contribute to the development of CVD. In addition, fibrinogen concentrations were strongly associated with BF. It is well know that fibrinogen concentrations correlate with BMI and BF [29,30], but the nature of this association is unknown. Although correlations do not imply causality, it is feasible that white adipose tissue plays a role in the regulation of fibrinogen concentrations. This might be explained by the increased production of IL- 6 in adipose tissue of obese patients [31], given the fact that this cytokine has been shown to induce fibrinogen expression in the liver [32]. If this is the case, however, a correlation between BF and CRP, would have been expected since this marker has also been shown to be regulated by IL-6 [33]. Another possible explanation resides in the potential regulation of fibrinogen concentrations by leptin through the induction of hepatic expression of fibrinogen. In our study, this possibility is supported by the strong correlation observed between circulating leptin and fibrinogen concentrations. In addition,
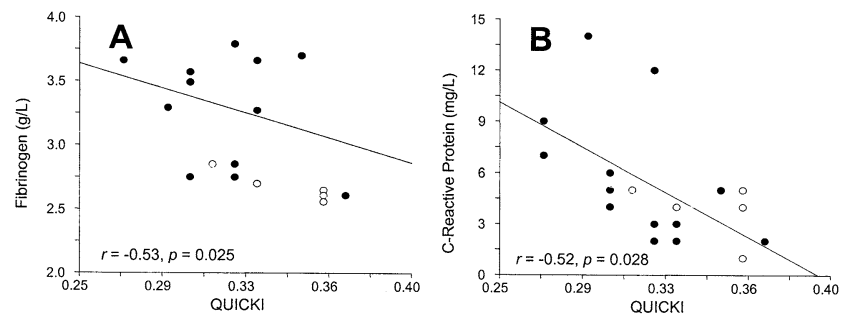

Fig. 3. Correlations of fibrinogen concentrations (A) and C-reactive protein (B) with the QUICKI of obese $(\mathbf{O})$, or nonobese $(\bigcirc)$ patients. Pearson's correlation coefficient $(r)$ and $p$ values are indicated.
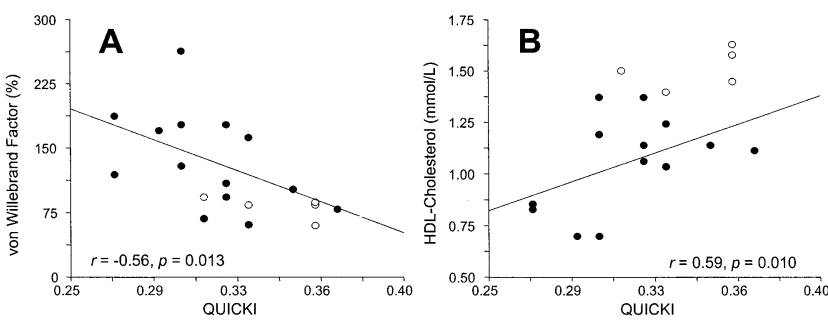

Fig. 4. Correlations of von Willebrand factor (A) and HDL-cholesterol (B) with the QUICKI of obese $(\boldsymbol{)})$, or nonobese $(\bigcirc)$ patients. Pearson's correlation coefficient $(r)$ and $p$ values are indicated.

the main finding of this work is that blood leptin concentrations may be a predictor of blood fibrinogen concentrations, given the fact that the association between them is conserved after adjustment for BF. This possibility would be in accordance with the proinflammatory role attributed to leptin [34]. An alternative explanation is that leptin resistance and not leptin itself increases fibrinogen concentrations. This possibility is reinforced by the fact that obese Zucker rats, which lack functional leptin receptors, and hence are a model of leptin resistance, have higher concentrations of fibrinogen than normal rats [35]. Whether the association of fibrinogen and leptin concentrations is due to a direct effect of leptin or to leptin resistance requires further experiments in which leptin resistance in humans is assessed. The association between fibrinogen and leptin has been previously observed in two studies [7,29]. However, in both of them, the relation was not observed after adjustment for BF or BMI. The present study suggests that increased $\mathrm{BF}$ contributes to the development of a prothromboticproinflammatory state and that leptin specifically correlates with fibrinogen, suggesting that high leptin concentrations lead to the achievement of this condition, therefore leading to obesity-related disorders.

Despite a $50 \%$ increase in CRP concentrations in obese patients compared to controls, no statistical significance was reached. Several studies have shown that CRP is elevated in human obesity $[36,37]$ and that it is correlated with indicators of adiposity [37-41]. These discrepancies may be explained taking into account several methodological aspects of the present study. First, the limited sample size raises the possibility of a lack of statistical strength. Second, several factors such as smoking, hypertension, and treatment with lipid-lowering or antihypertensive drugs may be confounding factors. In addition, our population sample of obese subjects may not be representative of central obesity, in which CRP concentrations are clearly correlated with BF [42]. However, in our study, CRP was significantly correlated with leptin concentrations. This association, which was not observed after adjustment for $\mathrm{BF}$ in multivariate regression analysis, is in agreement with previous studies $[13,41,43]$ and suggests that, in addition to leptin, another factor altered in obesity may be involved in the obesityinduced increase in CRP.

The pronounced increase in $\mathrm{vWF}$ observed in obese 
patients confirms that obesity has an adverse effect on the endothelium [27,28]. However, vWF did not show a significant correlation with either BF or leptin. Therefore, the increased vWF concentrations may be secondary to the dyslipidemia or insulin resistance observed [44]. Our results do not support an effect of increased adipose mass on plasma homocysteine concentrations. These results are in agreement with other published work [45,46], although some authors have found a weak correlation between plasma homocysteine and BMI [47].

Fibrinogen, CRP and vWF were negatively correlated with the QUICKI index. Interestingly, HDL-cholesterol was positively correlated with the QUICKI. Our data corroborate previous findings [48] and indicate that insulin resistance may, by itself or as a consequence of increased fat mass, induce endothelial dysfunction and inflammation. Taken together, these results confirm the marked involvement of insulin resistance associated to increased fat mass in the development of CVD. Nevertheless, prospective studies are needed to asses whether there is a simple association or a causal relationship between insulin resistance and high concentrations of fibrinogen, CRP and vWF and low concentrations of HDL-cholesterol.

In conclusion, these results indicate that men with high levels of $\mathrm{BF}$ have increased circulating prothromboticproinflammatory factors. Our work further strengthens the possibility that this relation is, at least in part, mediated by hyperleptinemia and insulin resistance. In addition, our results underline the role of leptin as an independent predictor of plasma fibrinogen concentrations.

\section{Acknowledgements}

The valuable assistance in body composition measurements and software package design of Loly Millán and Raquel Ordoñez is gratefully acknowledged.

\section{References}

[1] Mokdad AH, Bowman BA, Ford ES, Vinicor F, Marks JS, Koplan JP. The continuing epidemics of obesity and diabetes in the United States. JAMA 2001;286:1195-200.

[2] Popkin BM. The nutrition transition and obesity in the developing world. J Nutr 2001;131:871S-3S.

[3] National Task Force on the Prevention and Treatment of Obesity. Overweight, obesity, and health risk. Arch Intern Med 2000;160: 898-904.

[4] Frühbeck G, Gómez-Ambrosi J, Muruzábal FJ, Burrell MA. The adipocyte: a model for integration of endocrine and metabolic signaling in energy metabolism regulation. Am J Physiol Endocrinol Metab 2001;280:E827-47.

[5] Frühbeck G. A heliocentric view of leptin. Proc Nutr Soc 2001;60: 301-18.

[6] Söderberg S, Ahrén B, Stegmayr B, et al. Leptin is a risk marker for first-ever hemorrhagic stroke in a population-based cohort. Stroke 1999;30:328-37.
[7] Söderberg S, Olsson T, Eliasson M, Johnson O, Ahrén B. Plasma leptin levels are associated with abnormal fibrinolysis in men and postmenopausal women. J Intern Med 1999;245:533-43.

[8] Agata J, Masuda A, Takada M, et al. High plasma immunoreactive leptin level in essential hypertension. Am J Hypertens 1997;10:1171-4.

[9] Parhami F, Tintut Y, Ballard A, Fogelman AM, Demer LL. Leptin enhances the calcification of vascular cells: artery wall as a target of leptin. Circ Res 2001;88:954-60.

[10] Leyva F, Anker SD, Egerer K, Stevenson JC, Kox WJ, Coats AJ. Hyperleptinaemia in chronic heart failure. Relationships with insulin. Eur Heart J 1998;19:1547-51.

[11] Winnicki M, Phillips BG, Accurso V, et al. Independent association between plasma leptin levels and heart rate in heart transplant recipients. Circulation 2001;104:384-6.

[12] Leyva F, Godsland IF, Ghatei M, et al. Hyperleptinemia as a component of a metabolic syndrome of cardiovascular risk. Arterioscler Thromb Vasc Biol 1998;18:928-33.

[13] Wallace AM, McMahon AD, Packard CJ, et al. Plasma Leptin and the Risk of Cardiovascular Disease in the West of Scotland Coronary Prevention Study (WOSCOPS). Circulation 2001;104:3052-6.

[14] Clinical Guidelines on the Identification, Evaluation, and Treatment of Overweight, and Obesity in adults. Available at: http://www.nhlbi.nih.gov/guidelines, 1998.

[15] Sardinha LB, Lohman TG, Teixeira PJ, Guedes DP, Going SB. Comparison of air displacement plethysmography with dual-energy $\mathrm{X}$-ray absorptiometry and 3 field methods for estimating body composition in middle-aged men. Am J Clin Nutr 1998;68:786-93.

[16] Elia M, Ward LC. New techniques in nutritional assessment: body composition methods. Proc Nutr Soc 1999;58:33-8.

[17] Wells JC, Fuller NJ. Precision of measurement and body size in whole-body air-displacement plethysmography. Int J Obes Relat Metab Disord 2001;25:1161-7.

[18] Trinder P. Determination of blood glucose using an oxidase-peroxidase system with a non-carcinogenic chromogen. J Clin Pathol 1969; 22:158-61.

[19] Friedewald WT, Levy RI, Fredrickson S. Estimation of the concentration of low density lipoprotein cholesterol in plasma, without the use of preparative ultra-centrifuge. Clin Chem 1972;18:499-502.

[20] Clauss A. Gerinnungsphysiologische Schnellmethode zur Bestimmung des Fibrinogens. Acta Haematol 1957;17:237-40.

[21] Katz A, Nambi SS, Mather K, et al. Quantitative insulin sensitivity check index: a simple, accurate method for assessing insulin sensitivity in humans. J Clin Endocrinol Metab 2000;85:2402-10.

[22] Hubert HB, Feinleib M, McNamara PM, Castelli WP. Obesity as an independent risk factor for cardiovascular disease: a 26-year follow-up of participants in the Framingham Heart Study. Circulation 1983;67:968-77.

[23] Manson JE, Colditz GA, Stampfer MJ, et al. A prospective study of obesity and risk of coronary heart disease in women. N Engl J Med 1990;322:882-9.

[24] Al Suwaidi J, Higano ST, Hamasaki S, Holmes DR, Lerman A. Association between obesity and coronary atherosclerosis and vascular remodeling. Am J Cardiol 2001;88:1300-3.

[25] Eckel RH, Krauss RM, for the AHA Nutrition Committee. American Heart Association call to action: Obesity as a major risk factor for coronary heart disease. Circulation 1998;97:2099-100.

[26] Cigolini M, Targher G, Bergamo Andreis IA, Tonoli M, Agostino G, De Sandre G. Visceral fat accumulation and its relation to plasma hemostatic factors in healthy men. Arterioscler Thromb Vasc Biol 1996;16:368-74.

[27] De Pergola G, De Mitrio V, Giorgino F, et al. Increase in both pro-thrombotic and anti-thrombotic factors in obese premenopausal women: relationship with body fat distribution. Int J Obes Relat Metab Disord 1997;21:527-35. 
[28] Blann AD, Bushell D, Davies A, Faragher EB, Miller JP, McCollum $\mathrm{CN}$. von Willebrand factor, the endothelium, and obesity. Int J Obes Relat Metab Disord 1993;17:723-5.

[29] Chu N, Spiegelman D, Hotamisligil GS, Rifai N, Stampfer M, Rimm EB. Plasma insulin, leptin, and soluble TNF receptors levels in relation to obesity-related atherogenic and thrombogenic cardiovascular disease risk factors among men. Atherosclerosis 2001;157:495503 .

[30] Festa A, D'Agostino R, Williams K, et al. The relation of body fat mass and distribution to markers of chronic inflammation. Int $\mathrm{J}$ Obes Relat Metab Disord 2001;25:1407-15.

[31] Roytblat L, Rachinsky M, Fisher A, et al. Raised interleukin-6 levels in obese patients. Obes Res 2000;8:673-5.

[32] Fuller GM, Zhang Z. Transcriptional control mechanism of fibrinogen gene expression. Ann N Y Acad Sci 2001;936:469-79.

[33] Yu H, Rifai N. High-sensitivity C-reactive protein, and atherosclerosis: from theory to therapy. Clin Biochem 2000;33:601-10.

[34] Loffreda S, Yang SQ, Lin HZ, et al. Leptin regulates proinflammatory immune responses. FASEB J 1998;12:57-65.

[35] Herbert JM, Bernat A, Chatenet-Duchene L. Effect of ciprofibrate on fibrinogen synthesis in vitro on hepatoma cells and in vivo in genetically obese Zucker rats. Blood Coagul Fibrinolysis 1999;10:239-44.

[36] Visser M, Bouter LM, McQuillan GM, Wener MH, Harris TB. Elevated C-reactive protein levels in overweight, and obese adults. JAMA 1999;282:2131-5.

[37] Lemieux I, Pascot A, Prud'homme D, et al. Elevated C-reactive protein: another component of the atherothrombotic profile of abdominal obesity. Arterioscler Thromb Vasc Biol 2001;21:961-7.

[38] Bastard JP, Jardel C, Delattre J, Hainque B, Bruckert E, Oberlin F. Evidence for a link between adipose tissue interleukin- 6 content and serum C-reactive protein concentrations in obese subjects. Circulation 1999;99:2221-2.
[39] Festa A, D'Agostino R, Howard G, Mykkanen L, Tracy RP, Haffner SM. Chronic subclinical inflammation as part of the insulin resistance syndrome: the Insulin Resistance Atherosclerosis Study (IRAS). Circulation 2000;102:42-7.

[40] Forouhi NG, Sattar N, McKeigue PM. Relation of C-reactive protein to body fat distribution and features of the metabolic syndrome in Europeans and South Asians. Int J Obes Relat Metab Disord 2001; 25:1327-31.

[41] van Dielen FMH, van't Veer C, Schols AM, Soeters PB, Buurman WA, Greve JWM. Increased leptin concentrations correlate with increased concentrations of inflammatory markers in morbidly obese individuals. Int J Obes Relat Metab Disord 2001;25:1759-66.

[42] Yudkin JS, Stehouwer CD, Emeis JJ, Coppack SW. C-reactive protein in healthy subjects: associations with obesity, insulin resistance, and endothelial dysfunction: a potential role for cytokines originating from adipose tissue? Arterioscler Thromb Vasc Biol 1999;19:972-8.

[43] Cleland SJ, Sattar N, Petrie JR, Forouhi NG, Elliott HL, Connell JM. Endothelial dysfunction as a possible link between C-reactive protein levels and cardiovascular disease. Clin Sci 2000;98:531-5.

[44] Blann AD, Davis A, Miller JP, McCollum CN. Von Willebrand factor and soluble E-selectin in hyperlipidaemia: relationship to lipids and vascular disease. Am J Hematol 1997;55:15-23.

[45] Das S, Reynolds T, Patnaik A, Rais N, Fink LM, Fonseca VA. Plasma homocysteine concentrations in type II diabetic patients in India: relationship to body weight. J Diabetes Complications 1999;13:200-3.

[46] Yuan J-M, Yu MC. Effect of obesity on plasma homocysteine: author reply. Am J Clin Nutr 2001;74:558-9.

[47] Jacques PF, Bostom AG, Wilson PW, Rich S, Rosenberg IH, Selhub J. Determinants of plasma total homocysteine concentration in the Framingham Offspring cohort. Am J Clin Nutr 2001;73:613-21.

[48] Meigs JB, Mittleman MA, Nathan DM, et al. Hyperinsulinemia, hyperglycemia, and impaired hemostasis: the Framingham Offspring Study. JAMA 2000;283:221-8. 